\title{
Effects of inlet momentum and orientation on the hydraulic performance of water storage tanks
}

\author{
Manoel Lucas Machado Xavier ${ }^{1}$ • Johannes Gérson Janzen ${ }^{1}$
}

Received: 24 September 2015/Accepted: 15 July 2016/Published online: 27 July 2016

(c) The Author(s) 2016. This article is published with open access at Springerlink.com

\begin{abstract}
The influence of inlet momentum and inlet orientation on hydraulic performance of cylindrical water process tanks were investigated using a factorial design strategy. The hydraulic performance of the tanks was assessed with a computational fluid dynamics (CFD) model, which calculated the flow fields and the residence time distribution (RTD). RTDs were used to quantify the tanks hydraulic performance using hydraulic indexes that represent short-circuiting, mixing, and moment. These indexes were later associated with the effluent fraction of disinfectant (inlet and outlet disinfectant ratio). For small depth-to-diameter ratios, the inlet orientation and the inlet momentum were the most important factors regarding the hydraulic indexes and the effluent fraction of disinfectant, respectively. A poor correlation was obtained between the hydraulic indexes and the effluent fraction of disinfectant, indicating that they are not good predictors for water quality. For large depth-to-diameter ratios, the inlet orientation had the most significant effect on both the hydraulic indexes and effluent fraction of disinfectant. The short-circuiting and mixing indexes presented a good correlation with water quality for this case.
\end{abstract}

Keywords Numerical simulations - Computational fluid dynamics (CFD) - Residence time distribution (RTD) . Water quality $\cdot$ Factorial design

Manoel Lucas Machado Xavier

mavier89@gmail.com

Johannes Gérson Janzen

johannesjanzen@gmail.com

1 Federal University of Mato Grosso do Sul (UFMS), Campo Grande, MS, Brazil

\section{List of symbols}

C Tracer concentration $\left(\mathrm{kg} \mathrm{m}^{-3}\right)$

$C_{\text {o }} \quad$ Average tracer concentration $\left(\mathrm{kg} \mathrm{m}^{-3}\right)$

$C^{\prime}(\theta)$ Dimensionless RTD function

CFD Computational fluid dynamics

$D \quad$ Tank diameter $(\mathrm{m})$

$d \quad$ Inlet diameter (m)

$D_{f} \quad$ Molecular diffusivity $\left(\mathrm{m}^{2} \mathrm{~s}^{-1}\right)$

$D_{t} \quad$ Eddy diffusivity $\left(\mathrm{m}^{2} \mathrm{~s}^{-1}\right)$

$H \quad$ Water depth (m)

IO Inlet orientation

$k \quad$ Rate constant $\left(\right.$ day $\left.^{-1}\right)$

$M \quad$ Inlet jet momentum $\left(\mathrm{m}^{4} \mathrm{~s}^{-2}\right)$

$M_{0} \quad$ Zeroth moment of the dimensionless RTD function about the origin

$M_{1} \quad$ First moment of the dimensionless RTD function about the origin

$M_{2} \quad$ Second moment of the dimensionless RTD function about the origin

MI Moment index

$M_{\mathrm{t}} \quad$ Tracer mass $(\mathrm{kg})$

$Q \quad$ System volumetric flow rate $\left(\mathrm{m}^{3} \mathrm{~s}^{-1}\right)$

RTD Residence time distribution

Sc Turbulent Schmidt number

$t \quad$ Dimensional time (s)

$U \quad$ Velocity $\left(\mathrm{m} \mathrm{s}^{-1}\right)$

$U_{\text {inlet }}$ Inlet velocity $\left(\mathrm{m} \mathrm{s}^{-1}\right)$

$V \quad$ Volume of fluid in the system $\left(\mathrm{m}^{3}\right)$

$X \quad$ Fraction of pollutant remaining over time for firstorder reactions

$\tau \quad$ Theoretical residence time (s)

$v_{\mathrm{t}} \quad$ Eddy viscosity coefficient $\left(\mathrm{m}^{2} \mathrm{~s}^{-1}\right)$

$\theta \quad$ Dimensionless time

$\theta_{10}$ Dimensionless time necessary for $10 \%$ of the tracer to leave the system

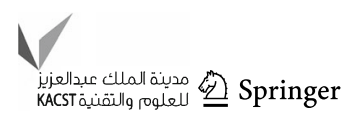




\section{Introduction}

Treated water storage tanks are very common structures inside a water supply system, being usually designed and operated to meet hydraulic requirements such as: ensure the reliability of supply, maintain pressure, equalize pumping and treatment rates and improve operational flexibility and efficiency (NBR 12217 1994; AWWA 2002; Walski 2000). From a water quality standpoint, however, the impact of these tanks is often negative. The longer the water remains in a storage tank, the amount of disinfectant removed becomes greater. This can promote microbial regrowth in the distribution system, leading to taste and odor problems and increased survivability of human pathogens; it can also enhance the growth of harmful disinfectant by-products (Rossman and Grayman 1999; United States Environmental Protection Agency 2002). Therefore, design and operation guidelines should aim to minimize the water residence time in storage tanks to improve water quality and mitigate water disinfection costs.

In practice, each parcel of water may have a unique residence time affected by physical properties (e.g., water density), flow type (e.g., inlet momentum) and geometric parameters (e.g., water depth) of a tank. Therefore, estimation of residence time distribution (RTD) of each parcel of water is important, because they are used to calculate expected hydraulic and water quality efficiencies for specific designs. Although a number of field (Palau et al. 2007; Grayman 2000; Stamou 2002), laboratorial (Rossman and Grayman 1999; Tian and Roberts 2008; Manjula et al. 2010), and computational (Patwardhan 2002; Stamou 2002; Marek et al. 2007; Raja et al. 2007, 2008; Stamou 2008; Zhang et al. 2012, 2013, 2014; Xavier et al. 2014) experiments have been carried out to investigate the influence of design and operation factors upon hydraulic and water quality indexes, they are inconclusive on at least four issues.

Firstly, there is very little information available regarding the effect of design factors on hydraulic and water quality indicators other than mixing time (the time needed for a known amount of added tracer material to reach a specific degree of uniformity in the tank) (Kalaichelvi et al. 2007). Mixing time is an indicator appropriate for measuring the performance of a storage tank if it is viewed as a mixing device. However, it is not clear if it can be expected all the water to mix before some of it leave the tank due to the enormity of their size (Van der Walt 2002). Therefore, although some experiments have been carried out in water storage tanks, there is very little information available about the effect of physical properties, flow type, and geometric parameters upon hydraulic and water quality indexes other than mixing time.
Secondly, to the authors knowledge, all studies used a poor experimental design, namely a one-factor-at-a-time strategy. In this strategy, design factors (e.g., inlet momentum, inlet orientation, and depth-to-diameter ratio) are analyzed by changing one factor at a time while holding the rest constant. However, a thorough investigation of the effects of the factors, along with their mutual interaction, is desirable for a better understanding of the subject. For example, Rossman and Grayman (1999) found that the main effect of inlet orientation (vertical or horizontal) is nearly zero. Therefore, we would be tempted to conclude that there is no effect of inlet orientation upon mixing time. However, the effect of inlet orientation may depend on the levels of another factor such as inlet momentum. If this is the case, then knowledge of the interaction between inlet orientation and inlet momentum is more useful than the knowledge of the main effect of inlet orientation. A significant interaction can mask the significance of main effects (Montgomery and Runger 2003). Consequently, Rossman and Grayman (1999) could have observed that the main effect of the inlet orientation may not have much meaning if a strong interaction is present. A factorial design strategy is the only way to compare these interactions (Brown and Berthouex 2010). One of the main advantages of this strategy, which is not possible in any one-factor-at-a-time strategy, is the possibility to estimate not only the main effects, but also all twofactor interactions and all higher-order interactions. In addition, the relative importance of all the factors can be evaluated simultaneously with a fewer number of experiments. Hence, the factorial design strategy can produce new and useful information.

Thirdly, many studies have been performed in physical models, which are not able to correctly reproduce both the turbulence and the decay rates of disinfectant and are unable to reproduce values of all the non-dimensional groups (e.g., Froude and Reynolds numbers) pertaining to the full-scale water storage tank (Shivaram 2007). These are particularly relevant in the study of the effect of physical properties, flow type, and geometric parameters upon hydraulic and water quality efficiency.

Finally, most of the studies used poor experimental techniques, i.e., invasive techniques with low spatial resolution (usually a few point-probe measurements in the tank) and high uncertainty that reveal little about the complex tracer concentration and velocity fields inside the tanks (Tian and Roberts 2008). Recently, Roberts et al. (2006) used a laser-induced fluorescence (LIF) technique to measure the temporal and spatial variations of tracer concentrations in water storage tanks, yielding far more detailed information than point-probe techniques. However, as Shivaram (2007) mentioned, the scanning planes 
of Roberts et al. (2006) did not capture the increase in water height for the fill-and-draw tank operation model and therefore mixing time is underestimated.

In order to address these issues, computational experiments were conducted using a computational fluid dynamics (CFD) tool that allows obtainment of the flow field and RTD curves. Simulations were conducted on two full-scale tank types (depth-to-diameter ratios) with different inlet orientations and inlet jet momentum. The goal was to determine the empirical effects of known design factors (inlet momentum and inlet orientation) on hydraulic performance indicators using a factorial design. The hydraulic indexes were related to the water quality.

\section{Residence time distribution (RTD) and Hydraulic performance indicators}

The analysis of residence time distribution (RTD) functions originating from tracer studies is one of the main tools for the assessment of hydraulic performance in water storage tanks. RTDs can be obtained by an instantaneous injection of a known quantity of tracer mass, $M_{\mathrm{t}}$, at the inlet section of the system and the subsequent measuring of the tracer concentration, $C$, along time, $t$, at its outlet section. In order to allow direct comparison of measured RTDs having dissimilar conditions (e.g., different volumes, flow rates, and tracer mass), they are usually presented in its normalized form (Werner and Kadlec 1996; Wahl et al. 2010). The dimensionless RTD function, $C^{\prime}(\theta)$, and the dimensionless time, $\theta$, can be defined, respectively, as:

$C^{\prime}(\theta)=\frac{C(\theta) V}{M_{t}} \tau$

$\tau=\frac{V}{Q}$

$\theta=\frac{t Q}{V}$

where $V$ is the system volume, $Q$ is the system volumetric flow rate and $\tau$ is the theoretical (or nominal) residence time. The zeroth $\left(M_{0}\right)$, first $\left(M_{1}\right)$, and second $\left(M_{2}\right)$ moment of the dimensionless RTD function about the origin are defined as, respectively:

$$
\begin{aligned}
M_{0} & =\int_{0}^{\infty} C^{\prime}(\theta) d \theta \\
M_{1} & =\int_{0}^{\infty} \theta C^{\prime}(\theta) d \theta \\
M_{2} & =\int_{0}^{\infty}\left(\theta-M_{1}\right)^{2} C^{\prime}(\theta) d \theta
\end{aligned}
$$

The zeroth moment provides the fraction of tracer mass recovered. If the inlet tracer mass is substituted by the outlet tracer mass, $M_{0}$ is always equal to unity. When $M_{0}=1$, the first moment is the centroid of the RTD. The second moment is the variance of the RTD, which accounts for the spread of the tracer over time.

Certain RTD characteristics can be used as water storage tank performance indicators (Van der Walt 2002). Although the performance indicators focus on the hydraulic efficiency, they should also mirror the expected water quality. In the present work, three indicators are used, which are grouped into three broad categories: (1) short circuit, (2) mixing, (3) moment. The short-circuit indicator is taken to be $\theta_{10}$, which is the time necessary for $10 \%$ of the tracer mass to leave the tank. As a mixing indicator, $M_{2}$ was used. The indexes chosen for categories (1) and (2) were suggested by Teixeira and Siqueira (2008) after evaluating different short-circuit and mixing indexes under three criteria: the correlation of the index to the physical phenomenon it is said to represent; the capability of the index to detect variation; and statistical variability of the index. The moment index (category 3) provides a hydraulic efficiency measurement that avoids reliance on short-circuiting and mixing indexes. In this study, the postnominal moment component, suggested by Wahl et al. (2010), was adopted. This approach considers hydraulic efficiency relative to the fraction of tracer exiting later as well as the juxtaposition of residence times about what is referred to as the nominal divisor in Fig. 1. This method assumes that the residence times of a completely efficient water storage tank will meet or fall to the right of the nominal divide. The portion of tracer exiting the storage tank later than the nominal divide adversely impacts water quality. The segment of the probability density function to the right of the nominal divide is considered inefficient, with more weight assigned to the more severely overdue

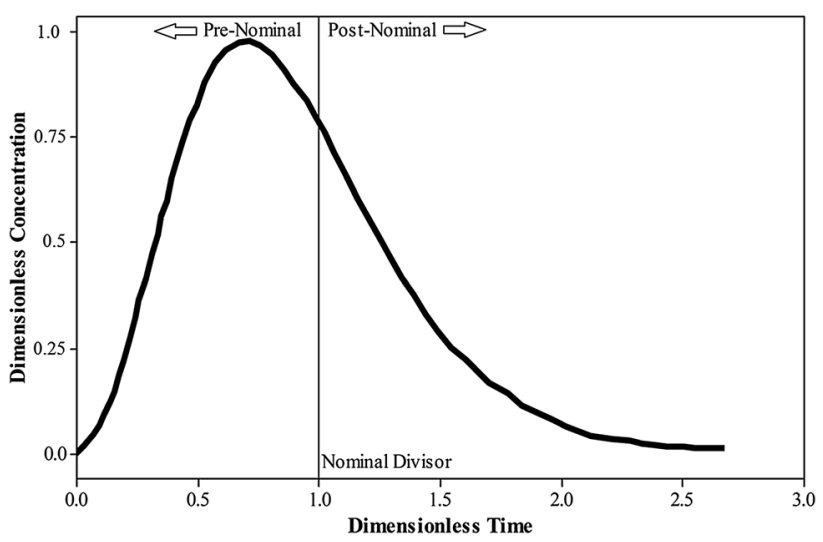

Fig. 1 Residence time distribution showing pre-nominal and postnominal components. Figure adapted from Wahl et al. (2010) 
residence times. If the bulk of tracer exiting has a close proximity to the nominal divide, then hydraulic efficiency is high. As more tracer exits earlier (in relation to the nominal divide), the hydraulic efficiency approaches zero. The post-nominal moment index is equal to:

$\mathrm{MI}=\int_{1}^{\infty}(\theta-1) C^{\prime}(\theta) d \theta$

\section{Materials and methods}

\section{Factorial design strategy for the CFD experiments}

A factorial design strategy was used to study the effects of all combinations of inlet momentum and orientation on four responses for two water-depth-to-tank-diameter ratios. The response variables for observing the hydraulic and water quality performance were $\theta_{10}, M_{2}$, MI, and $X$ (see definition of $X$ in Eq. 9). The two factors inlet momentum and inlet orientation were each investigated at two levels. This is a two-level, two-factor experimental design. Two factors at two levels gives four experimental conditions for each $\mathrm{H} /$ $D$ (Tables 1, 2; Fig. 2). For $H / D=0.25$, four experimental conditions were added to the two-level factorial design to obtain an independent estimate of error and to check for curvature. For $H / D=4$, the values considered for $M$ were $9.63 \times 10^{-5} \mathrm{~m}^{4} / \mathrm{s}^{2}$ (low level) and $1.38 \times 10^{-4} \mathrm{~m}^{4} / \mathrm{s}^{2}$ (high level). The inlet orientation was set between a horizontal inlet, $10 \mathrm{~cm}$ above the bottom (low level); and a vertical inlet, $10 \mathrm{~cm}$ from the sidewall (high level). For $H / D=0.25$, the values considered for $M$ were $1.23 \times 10^{-3} \mathrm{~m}^{4} / \mathrm{s}^{2}$ and $4.93 \times 10^{-1} \mathrm{~m}^{4} / \mathrm{s}^{2}$. The inlet orientation was set between a horizontal inlet, $10 \mathrm{~cm}$ above the bottom; and a vertical inlet, $10 \mathrm{~cm}$ from the sidewall. For both types of tanks, the outlet was located at the center of the bottom of the tank. The ranges of data tested were chosen based on characteristics found in typical Brazilian storage tanks; they were not intended to be representative of the entire range of field conditions, but rather intended to determine if the inlet momentum and inlet orientation had an effect on the responses. The effects of the factors of inlet momentum and inlet orientation were evaluated by determining the significance of main factors (main effect) and their interaction using Lenth's pseudo-standard error (PSE). The pseudo-standard error is based on the concept of sparse effects, which assumes the variation in the smallest effects is because of random error (MINITAB 2015). The main effect is defined as the change in response produced by a change in the level of the factor. The interaction between the factors examines the effects of inlet momentum at different levels of inlet orientation. Factorial design strategies are the only way to discover interactions between factors.

\section{CFD}

Initially the flow field was determined through 3D steady state simulations by solving the reynolds averaged navier-

Table 1 Design matrix of the $2^{2}$ factorial experimental design (with extra points), levels of independent variables ( $M$ and inlet orientation) and observed responses $\left(\theta_{10}, M_{2}, \mathrm{MI}, X\right)$ for $H / D=0.25$

\begin{tabular}{|c|c|c|c|c|c|c|c|c|c|}
\hline Experiment & $d(\mathrm{~m})$ & $\tau$ (day) & $M\left(\mathrm{~m}^{4} / \mathrm{s}^{2}\right)$ & Inlet orientation & Reynolds number & $\theta_{10}$ & $M_{2}$ & MI & $X$ \\
\hline 1 & 0.15 & 3.33 & $1.77 \times 10$ & Horizontal & $4.75 \times 104$ & 0.014 & 0.590 & 0.217 & 0.452 \\
\hline 2 & 0.07 & 3.33 & $7.09 \times 10$ & Horizontal & $9.50 \times 104$ & 0.052 & 0.687 & 0.309 & 0.392 \\
\hline 3 & 0.35 & 0.083 & $4.93 \times 10$ & Horizontal & $7.92 \times 105$ & 0.008 & 1.122 & 0.375 & 0.965 \\
\hline 4 & 0.18 & 3.33 & $1.23 \times 10$ & Horizontal & $3.96 \times 104$ & 0.001 & 0.602 & 0.236 & 0.471 \\
\hline 5 & 0.15 & 3.33 & $1.77 \times 10$ & Vertical & $4.75 \times 104$ & 0.123 & 0.450 & 0.209 & 0.389 \\
\hline 6 & 0.07 & 3.33 & $7.09 \times 10$ & Vertical & $9.50 \times 104$ & 0.131 & 0.614 & 0.173 & 0.358 \\
\hline 7 & 0.35 & 0.083 & $4.93 \times 10$ & Vertical & $7.92 \times 105$ & 0.143 & 0.482 & 0.233 & 0.965 \\
\hline 8 & 0.18 & 3.33 & $1.23 \times 10$ & Vertical & $3.96 \times 104$ & 0.116 & 0.448 & 0.205 & 0.395 \\
\hline
\end{tabular}

Table 2 Design matrix of the $2^{2}$ factorial experimental design, levels of independent variables ( $M$ and inlet orientation) and observed responses $\left(\theta_{10}, M_{2}\right.$, MI, $\left.X\right)$ for $H / D=4$

\begin{tabular}{|c|c|c|c|c|c|c|c|c|c|}
\hline Experiment & $d(\mathrm{~m})$ & $\tau$ (day) & $M\left(\mathrm{~m}^{4} / \mathrm{s}^{2}\right)$ & Inlet orientation & Reynolds number & $\theta_{10}$ & $M_{2}$ & MI & $X$ \\
\hline 9 & 0.15 & 3.33 & $1.38 \times 10-4$ & Horizontal & $1.33 \times 104$ & 0.018 & 0.673 & 0.250 & 0.490 \\
\hline 10 & 0.07 & 3.33 & $9.63 \times 10-5$ & Horizontal & $1.11 \times 104$ & 0.001 & 0.850 & 0.292 & 0.507 \\
\hline 11 & 0.35 & 3.33 & $1.38 \times 10-4$ & Vertical & $1.33 \times 104$ & 0.115 & 0.427 & 0.194 & 0.399 \\
\hline 12 & 0.18 & 3.33 & $9.63 \times 10-5$ & Vertical & $1.11 \times 104$ & 0.115 & 0.536 & 0.250 & 0.381 \\
\hline
\end{tabular}


Fig. 2 3D view and plane $x=0$ (plane $z-y)$ of the geometry of the tanks used in the computational simulations where, $A$ inlet; and $B$ outlet. The origin of the axis is at the outlet pipe
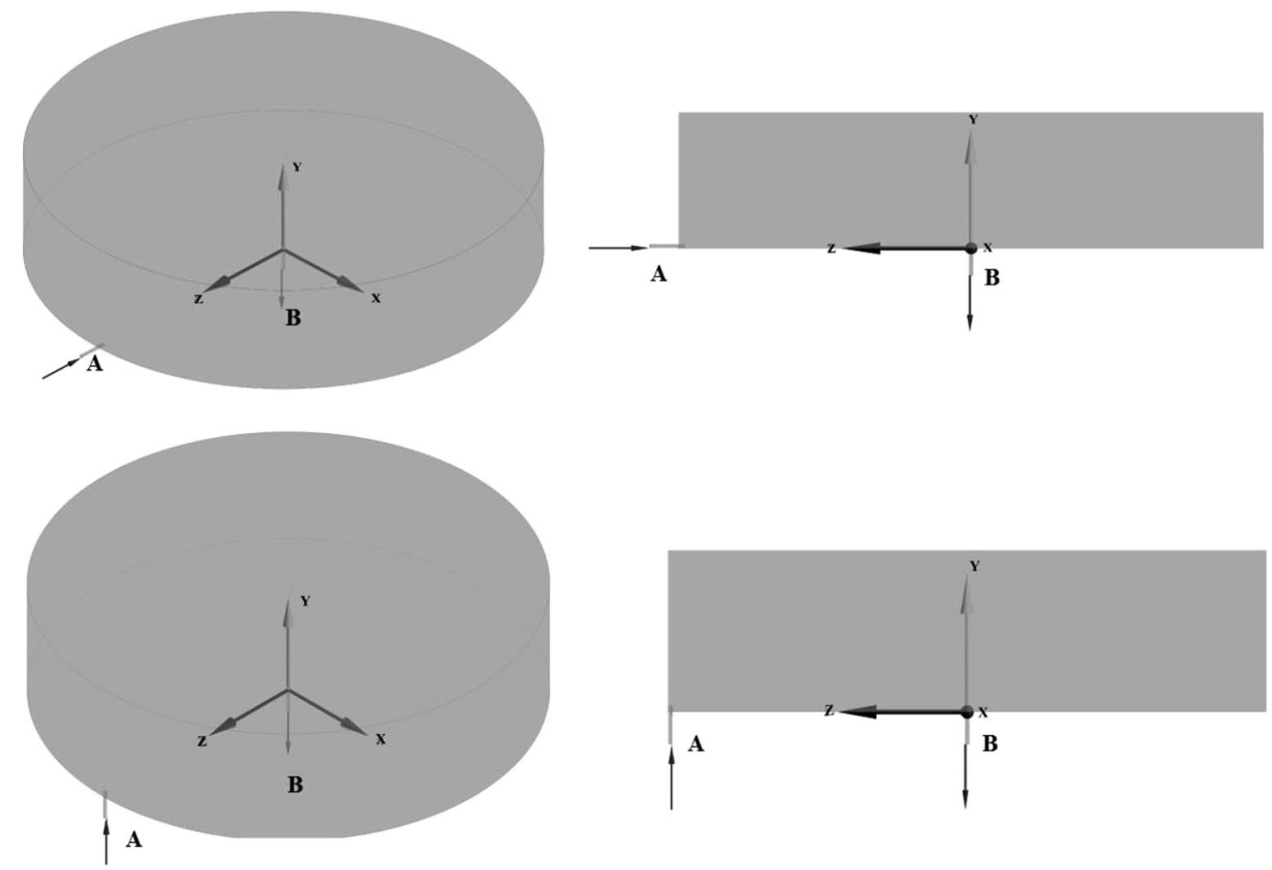

stokes (RANS) equations via the $\mathrm{k}-\varepsilon$ turbulence model using the commercial computational fluid dynamics (CFD) code ANSYS CFX ${ }^{\circledR}$ 14.5.7. The steady-state simplification is justified for tanks that are not subjected to large tank level fluctuations (Van der Walt 2002). Pressure-velocity coupling was achieved by using the semi-implicit method for pressure-linked equations (SIMPLE) algorithm. A second order upwind scheme was used for spatial discretization of the flow equations. The advection scheme chosen, as well as the turbulence numeric, was the high resolution. Boundary conditions were defined at the borders of the computational domain. A uniform flow was imposed at the inlet. At the outlet, an average static reference pressure of $0 \mathrm{~Pa}$ was specified. A no-slip boundary condition was applied at the walls. The free surface was considered a symmetry plane, which implies a zero gradient for all variables normal to that plane (Stamou 2002). Hence, the free surface was assumed to be flat.

Once the steady-state flow field was obtained, the transport of a scalar quantity $C$ was simulated by solving the three-dimensional Reynolds-averaged advection-diffusion equation:

$\frac{\partial C}{\partial t}+U_{j} \frac{\partial C}{\partial x_{j}}=\frac{\partial}{\partial x_{j}}\left(\left(D_{f}+D_{t}\right) \frac{\partial C}{\partial x_{j}}\right)$

where $t$ is the time, $U$ is the velocity, $D_{\mathrm{f}}$ is the molecular diffusivity and $D_{\mathrm{t}}\left(=v_{\mathrm{t}} / S c, v_{\mathrm{t}}\right.$ is eddy viscosity coefficient and $S c$ is the turbulent Schmidt number) is the eddy diffusivity. The turbulent Schmidt number, Sc, was 0.9. Equation 8 is based on the values of $U_{\mathrm{j}}$, which are obtained from the converged steady-state hydrodynamics simulation.
A pulse tracer study was conducted in each tank. At the inlet, a passive and conservative tracer was injected having a duration less than $2 \%$ of the nominal detention time and represented by a square step input. The scalar concentration was monitored at the outlet to produce the RTD curve for the tank. The tracer transport simulations ran until $95 \%$ of the tracer mass left the tank. The solute transport simulations were carried out using a time step that varied between 1 and $600 \mathrm{~s}$. For the time intervals where there was a high variation of concentration, the time step was smaller.

The full domain of the numerical grid for a typical simulation is shown in Fig. 3. The numerical code employs unstructured numerical grids, which permit a very accurate representation of the boundaries. The grid had a finer spacing at the inlet and outlet regions. After a series of preliminary calculations, the computational grids for the twelve cases ranged from $10^{4}$ to $10^{5}$ hexahedral elements. The preliminary results indicated that this grid was fine enough to capture the flow features that were important while providing a satisfactory computational time. More details of the governing equations, turbulence model, and algorithms can be found in the $\mathrm{CFX}^{\circledR}$ user's guide (ANSYS Inc. 2012).

\section{Results and discussion}

\section{Validation}

Prior to its application, the CFD model was validated experimentally by finding the RTD of Kipseli's tank in 

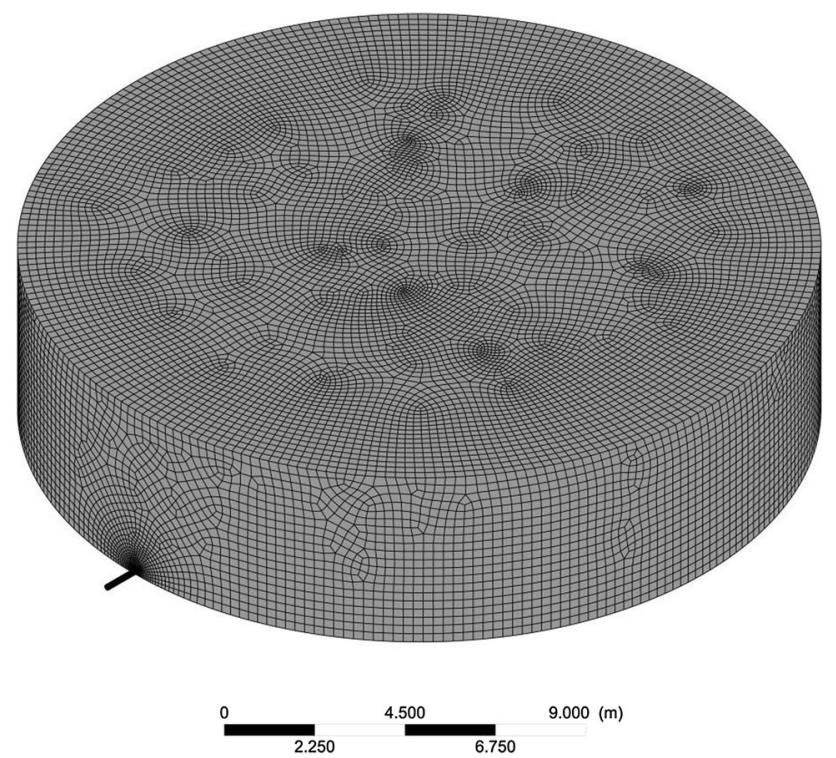

Fig. 3 Typical mesh used in the CFD simulations. It is possible to notice the refinement at the inlet region, where the velocity gradients are greater when compared to the rest of the tank

Athens, Greece (Stamou 2002), which has a horizontal section of $1560 \mathrm{~m}^{2}$. The water flows into the tank from a $600 \mathrm{~mm}$ inlet pipe at the bottom of the tank and exits via two $900 \mathrm{~mm}$ diameter pipes, placed in a hopper at the bottom of the tank. The 41 columns in the tank were disregarded to simplify the geometry. The nominal residence time is around $100 \mathrm{~min}$. A pulse tracer study was conducted by injecting a mass of sodium chloride (inlet concentration $C_{0}=0.07 \mathrm{~kg} / \mathrm{m}^{3}$ ) for approximately $3 \%$ of the nominal residence time into the inlet pipe of the tank. There is a good agreement between experimental and computational RTD data (Fig. 4), taking into consideration that only one RTD experiment has been performed and that $Q$ and $H$ were not constant during the field tracer experiment. At the first wave of the curve, the peak of the experimental curve is higher than both computational results. At the fifth and sixth waves of the curve the computational results displays a good agreement with the experimental data, as well as the later part of the curve, which has an exponential shape. For $t / \tau>0.75$, both experimental data and computational results almost coincide. The region where the computational results present the least agreement with the experimental data is at the second, third and fourth waves, where the computational results presents a similar behavior, but with a shorter period. The period, as commented by Stamou (2002), is the time needed for the tracer to complete a passage in a large recirculation region, which occupies almost $95 \%$ of the volume of the tank (figure not shown in the text). These shorter periods suggest that there is a higher level of mixing in most of the when compared to the CFD-model.

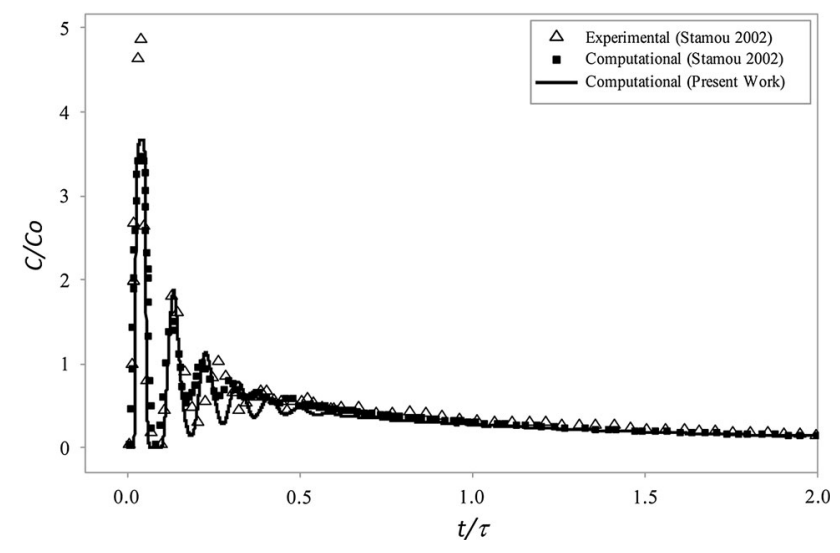

Fig. 4 Comparison between the experimental data and the computational results

As suggested by Stamou (2002), these differences can be partly attributed to the additional turbulence created by the 41 columns in the tank, which are not taken into account for in the CFD-model. Hence, considering that the CFDmodel is actually a simplification of a real tank geometry and operation, the resulting RTD exhibits a remarkable fidelity to the experimental RTD.

$H / D=0.25$

\section{Velocity field and streamlines}

Simulated distributions of the velocity magnitude and streamlines in planes $x y, y z$, and $x z$ are shown in Fig. 5 for $H / D=0.25$. The velocity $U$ was normalized by the inlet velocity, $U_{\text {inlet. }}$. For the horizontal inlet (Fig. 5), the circular jet near the bottom of the tank evolves into a wall jet along the tank's bottom wall. As the inlet jet went toward the opposite wall with high velocity, part of the flow was diverted towards the tank outlet, so that significant volumes of water exit the tank in a much lower time than the theoretical residence time, $\tau$. Despite using a different outlet configuration (the outlet was located on the floor opposite the inlet in the mid-plane) and depth-to-diameter ratio $(\mathrm{H} /$ $D$ oscillated between 0.8 and 0.9 ), Zhang et al. (2014) also found that part of the influent flows to the outlet directly. When the jet impinged on the opposite wall (Fig. 5), the flow was re-directed from a horizontal to a vertical direction inducing counter-clockwise circulations that consist mainly of vertical two-dimensional circulation cells in the back half of the tank (opposite the inlet wall). This behavior is consistent with the vertical flow structure observed by Maruyama et al. (1982). The horizontal flow field is dominated by recirculation regions. High velocities were observed in the outer parts of the recirculation regions. Very low velocities were found in the central areas 
Fig. 5 Isocontours of dimensionless velocities, $U /$ Uinlet, and streamlines for $H /$ $D=0.25$. a $x y$ planes $(z=-5$, 0 , and $5 \mathrm{~m})$; b $y z$ planes $(x=-5,0$, and $5 \mathrm{~m}) ; \mathbf{c} x z$ planes $(y=0.1$ and $3 \mathrm{~m})$ The left tank has and horizontal inlet orientation while the tank to the right has a vertical inlet orientation

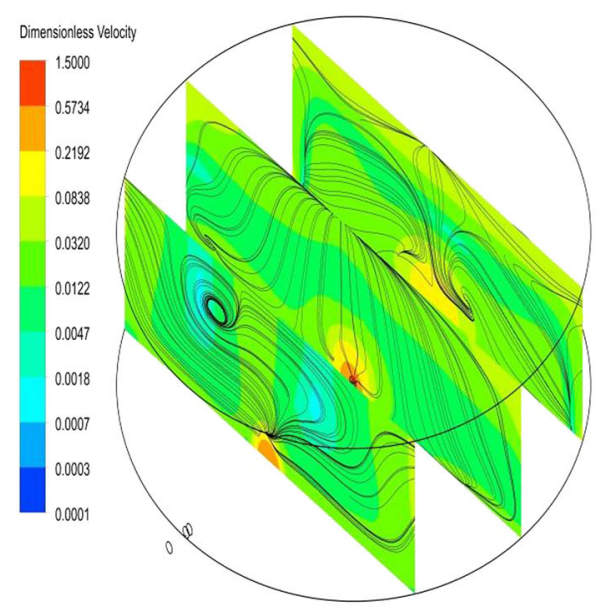

(a)
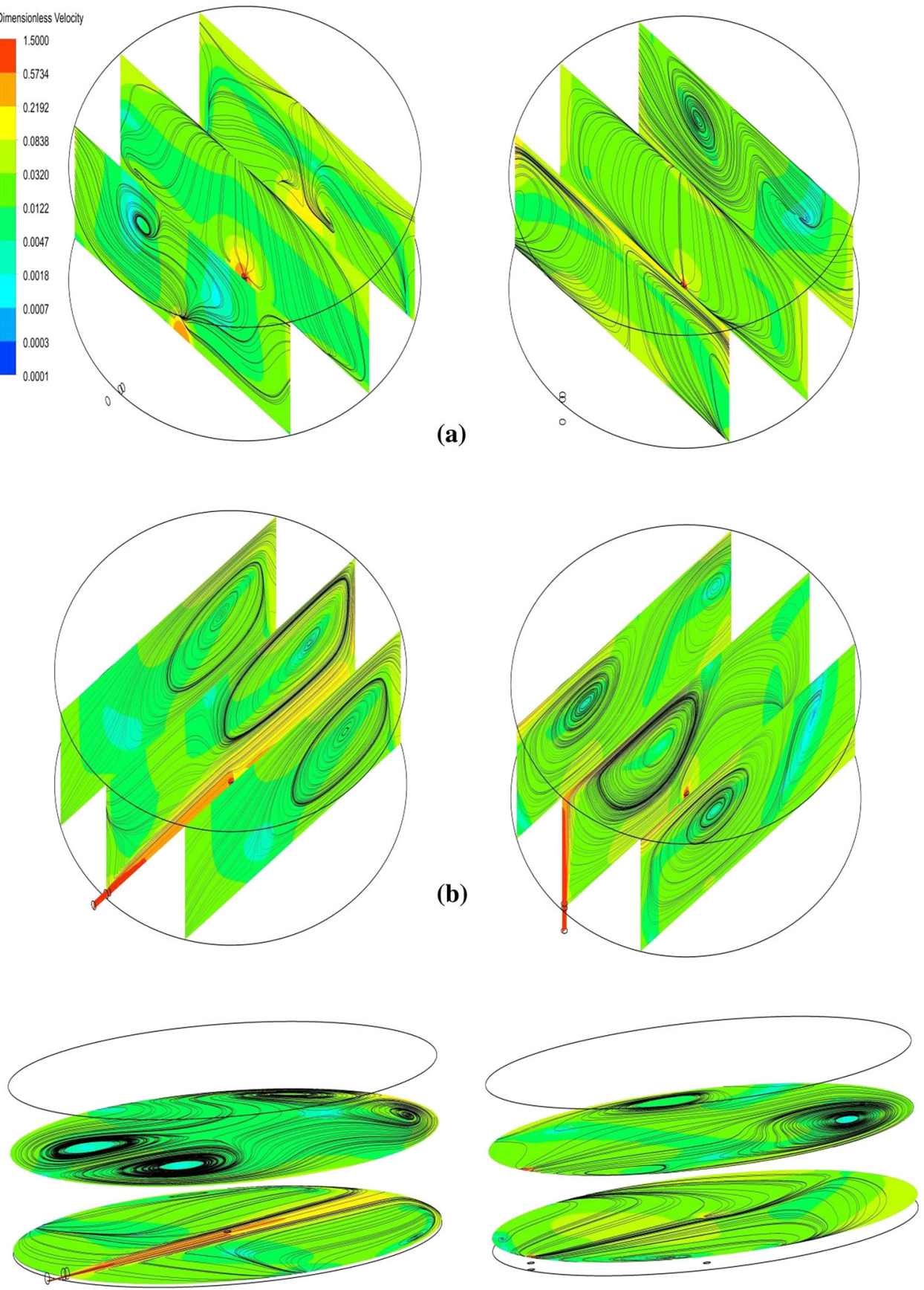

(c)

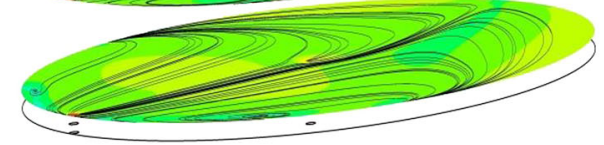

of the re-circulation regions. A similar horizontal flow pattern was also observed for our other horizontal inlet cases. Zhang et al. (2014) also reported the existence of recirculation regions for the horizontal flow field. When the inflow rate obtained by Zhang et al. (2014) was greater than the outflow rate, two big flow recirculation regions were found to occupy a large portion of the tank and two secondary flow recirculation regions were found near the outlet; when the inflow rate was less than the outflow rate, the big flow recirculation regions breaks into four.
For the vertical inlet (Fig. 5), flow enters the tank through the inlet as a jet and flows with high velocity towards the free surface. At the water surface, the upward flow was spread into one lobe towards the center and two circulation zones to the left and right of the central surface jet. As the water flows toward the center, it was diverted toward the tank bottom, creating a recirculation zone around an axis parallel to the $x$-axis. Some portion of this water gets back into the jet to mix with new water entering through the inlet. The other portion of water flows out 
(a)

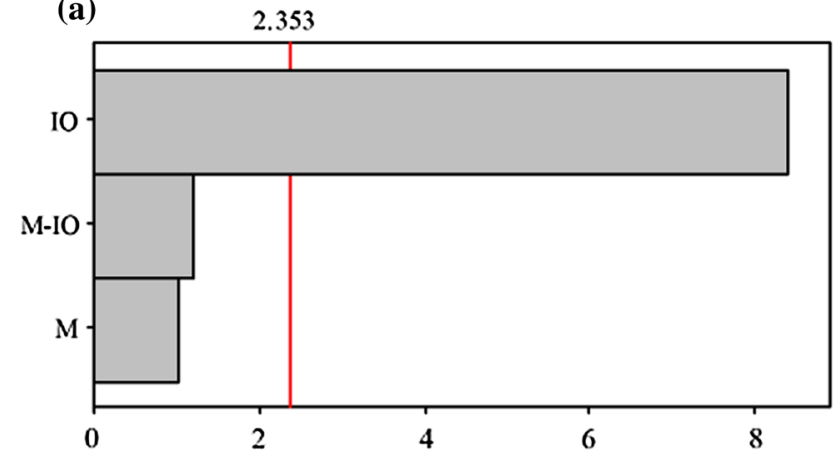

(c)

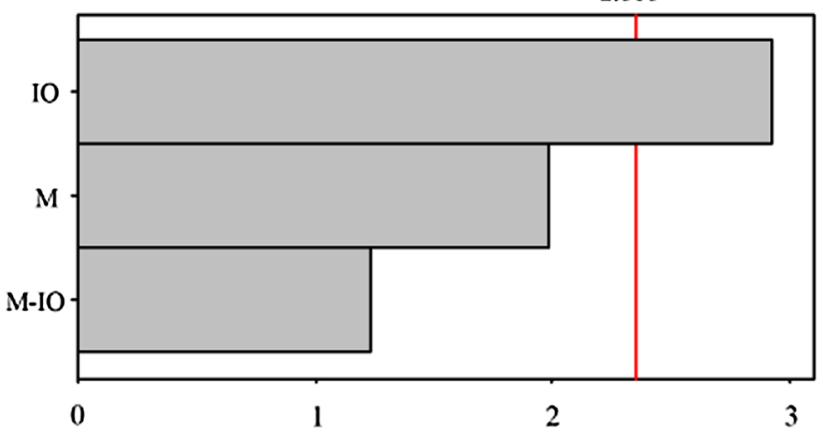

(b)

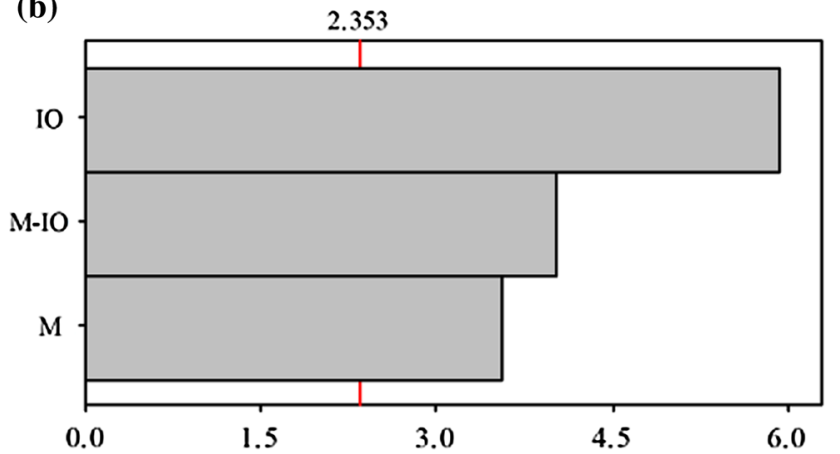

(d)

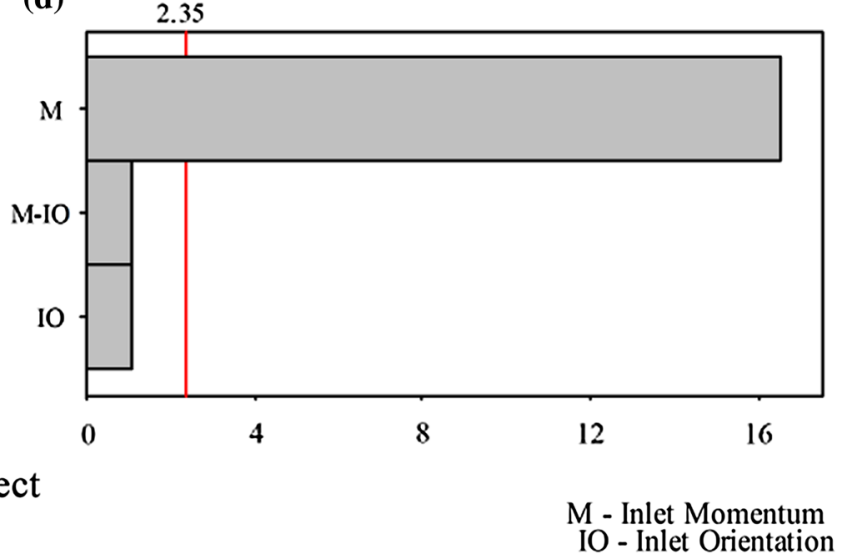

Fig. 6 Pareto charts of the effects for the 22 factorial design over: a $\theta_{10}$; b $M_{2}$; c MI; and $\mathbf{d} X$; for $H / D=0.25$

through the outlet. Again high velocities were found near the inlet, the outlet, and in the outer parts of the recirculation regions. Very low velocities were observed in the central areas of the re-circulation regions.

Tian and Roberts (2008) measured tracer concentration distributions using laser-induced fluorescence (LIF) for storage tanks with $H / D=0.25$ and two values of $M$, and no outlet. They found results that are consistent with our simulations. The inflowing jet was a region of high concentration. Mixed inflow separated from the water surface, forming a recirculation zone that gets back into the jet. More mixed inflow appeared near the tank wall opposite the jet due to flow that travels around the tank walls. After it appears in the center plane, it moves back toward the jet and is re-entrained by it. With a single outlet of the same diameter near the opposite wall, Tian and Roberts (2008) observed reduced recirculation.

\section{Hydraulics indicators}

In order to better understand the hydrodynamics processes, hydraulic indexes were calculated for the $H / D=0.25$ tanks (Table 1). The average of $\theta_{10}$ was low $\left(\theta_{10}=0.0735\right)$, indicating the presence of intense short- circuiting. In general, short-circuiting is never desirable because it reduces the effective volume of the storage tank and, consequently, disinfectant residual loss is increased. $\theta_{10}$ increased by 0.120 as the inlet orientation changed from horizontal to vertical. When inlet momentum $M$ increased, $\theta_{10}$ also slightly increased (0.018). The influence of the $M$ and IO (Inlet Orientation) interaction on $\theta_{10}$ was low (0.017). To establish if these effects are significant, the pareto charts were constructed (Fig. 6). The Pareto chart displays the relative importance of the main and interaction effects. The vertical line in the chart indicates the minimum statistically significant effect magnitude for a $90 \%$ confidence level. The interpretation of this chart demonstrated that the factor of inlet orientation is statistically significant for $\theta_{10}$. On the contrary, the inlet momentum and the interaction between inlet momentum and inlet orientation were not statistically significant. In other words, a vertical inlet diminished the short-circuiting.

The average $M_{2}$ effect was $0.624 . M_{2}$ is a quantitative description of the tanks mixing scale. According to ideal reactor models, an $M_{2}$ value close to 0 indicates plug flow while a value close to 1 indicates that the flow is closer to the complete mixing regime (Rossman and Grayman 1999). Generally, mixed flow is assumed to result in less 
disinfectant loss (Grayman 2000). If this is true, any $M_{2}<1$ increases the disinfectant loss. Mixing indicators ranged from a transitional flow (between mixed and plug) to a completely mixed tank (0.448 to 1.122$)$. The change in the inlet position from horizontal to vertical decreased $M_{2}$, while increasing the inlet momentum from low to high increased its value. The interaction $M$-IO was equal to 0.259 , i.e., the effect of inlet momentum was dependent on the level of inlet orientation. The effect of inlet orientation upon mixing was much stronger for a high inlet momentum than for a low inlet momentum. The sequence of the most important effects with respect to $M_{2}$ was found to be $\mathrm{IO}>M$-IO $>M$. All main effects and interactions were statistically significant.

The average MI was 0.245 . Since the MI values were close to zero ( $\mathrm{MI}=0.17-0.37$ ), the hydraulic efficiency is good. Inlet orientation plays a major role upon MI. Change in inlet position from horizontal to vertical decreased MI by 0.1 . The inlet momentum and the interaction between inlet momentum and inlet orientation were not statistically significant.

For first-order reactions, it is possible to determine the fraction of disinfectant $(X)$ remaining over time depending on some rate constant $k$ as follows (Wahl et al. 2010):

$X=\int_{0}^{\infty} \frac{C^{\prime}(\theta)}{\tau} e^{-k t} d t$

Considering $k=0.5 \mathrm{day}^{-1}$ (Grayman 2000), Table 1 presents the values for $X$. The average $X$ was 0.550 . The fraction of disinfectant varied from 0.36 to 0.96 . $X$ increased with the increase of $M$. Increasing $M$ from $1.23 \times 10^{-3}$ to $4.93 \times 10^{-1} \mathrm{~m}^{4} / \mathrm{s}^{2}$ increased $X$ by a maximum of $55 \%$. The main effect of inlet orientation and its interaction with the inlet momentum were not statistically significant for $X$.

In summary, the strongest influence on the hydraulic efficiency was the inlet orientation. The horizontal inlet orientation resulted in the best hydraulic efficiency. Previous studies considering mixing time have also observed the influence of inlet orientation on hydraulic efficiency (Maruyama et al. 1982; Dakshinamoorthy et al. 2006; Zughbi and Rakib 2004; Tian and Roberts 2008). However, contradictory results showed up about how the inlet orientation influences the hydraulic efficiency (Shivaram 2007). One of the reasons they show contradictory results might just come down to experimental design. Inlet momentum and the interaction between inlet momentum and inlet orientation also had influence on the hydraulic efficiency, particularly for the mixing index. The effect of inlet orientation upon mixing was much stronger for a high inlet momentum than for a low inlet momentum. In general, similar results have been reported in laboratory

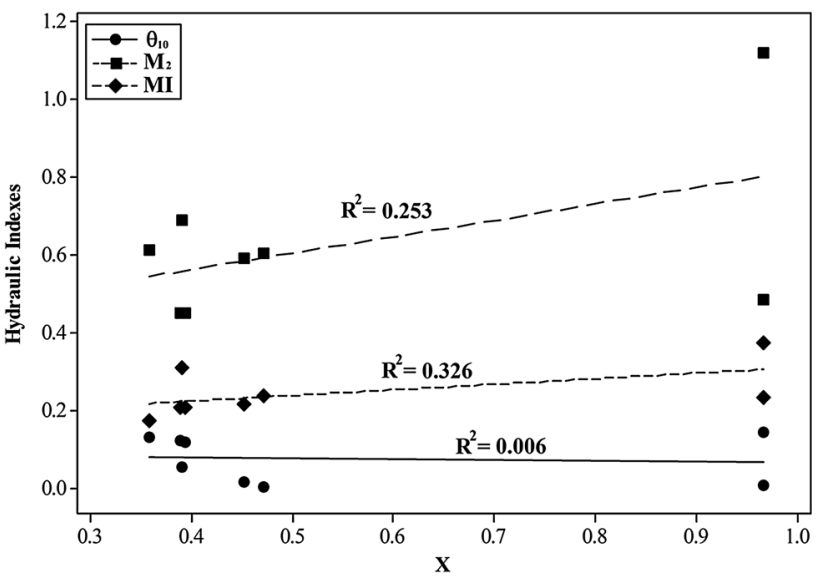

Fig. 7 Hydraulic indices plotted vs. effluent disinfectant fraction, $X$, for $H / D=0.25$. Regression lines are also displayed along the data displayed with $R^{2}$ values for $\theta_{10}, M_{2}$, and MI

Table 3 Average and main effects of $M$ and IO and their higher order interactions of the $2^{2}$ factorial design on the $\theta_{10}, M_{2}$, MI, and $X$ for $H$ / $D=0.25$

\begin{tabular}{|c|c|c|c|c|}
\hline Effect & $\theta_{10}$ & $M_{2}$ & MI & $X$ \\
\hline Average effect & 0.0735 & 0.624 & 0.245 & 0.550 \\
\hline \multicolumn{5}{|l|}{ Main effects } \\
\hline$M$ & +0.018 & +0.278 & +0.083 & +0.531 \\
\hline IO & +0.120 & -0.379 & -0.100 & -0.029 \\
\hline \multicolumn{5}{|c|}{ Two-factor interactions } \\
\hline$M-\mathrm{IO}$ & +0.017 & -0.259 & -0.042 & +0.029 \\
\hline
\end{tabular}

experiments (Tian and Roberts 2008). All these studies, however, evaluated the hydraulic efficiency using the mixing time indicator and they did not affirm the relative importance of inlet orientation, inlet momentum and their interaction.

Regarding water quality efficiency, the strongest influence was the inlet momentum. Since the order of importance of the factors that influence the hydraulic efficiency were different from those that influence the water quality efficiency, the hydraulic indexes should not demonstrate good correlation to the effluent disinfectant fraction $X$. This is confirmed by the low correlation between the hydraulic indexes and $X$ (see Fig. 7). Therefore, judging the water quality of a small depth-to-diameter ratio storage tank, based on traditional hydraulic indexes, should be avoided (Table 3).

\section{$H / D=4$}

\section{Velocity field and streamlines}

Simulated distributions of velocity magnitude and streamlines in the planes $x y, y z$, and $x z$ are shown in Fig. 8 for $H /$ 


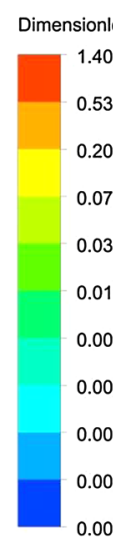

Dimensionles
1.4000
0.5389
0.2074
0.0799
0.0307
0.0118
0.0046
0.0018
0.0007
0.0003
0.0001
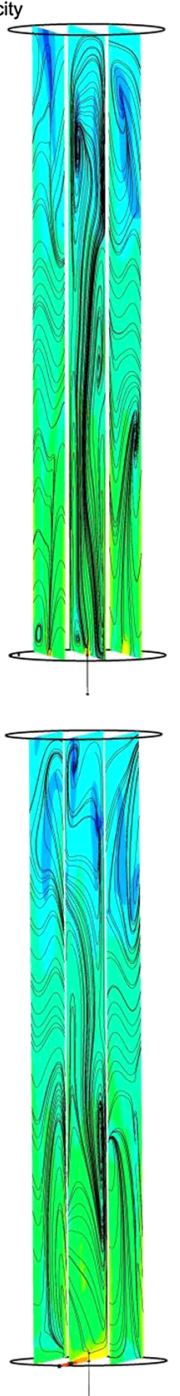

(b)

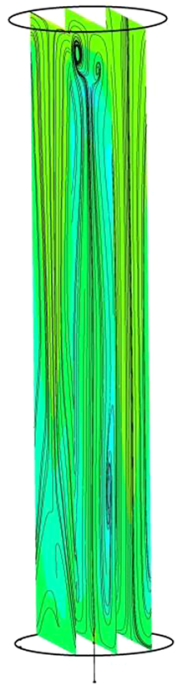

(a)
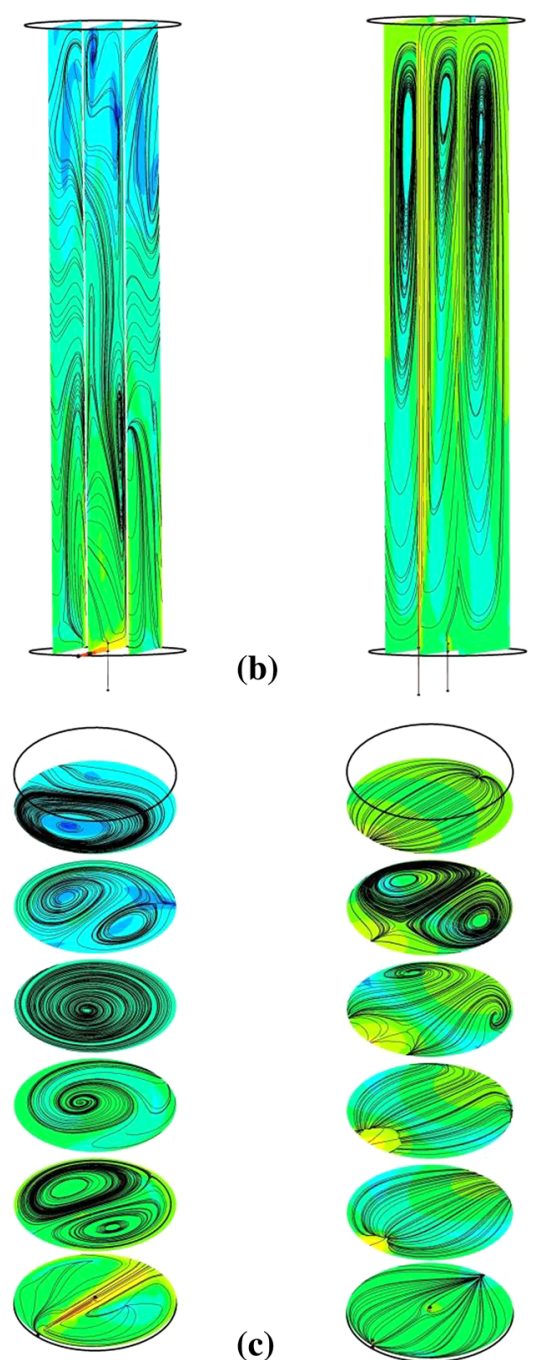

4 Fig. 8 Isocontours of dimensionless velocities, $U / U_{\text {inlet }}$, and streamlines for $H / D=4$. a $x y$ planes $(z=-1,0$, and $1 \mathrm{~m})$; b $y z$ planes $(x=-1,0$, and $1 \mathrm{~m}) ; \mathbf{c} x z$ planes $(y=0.1,3,6,9,12$, and $15 \mathrm{~m})$. The left tank has and horizontal inlet orientation while the tank to the right has a vertical inlet orientation

in the tanks with $H / D=0.25$, with the presence of a shortcircuit zone governed by the inlet jet. When the jet hits the opposite wall and heads to the upper parts of the tank it loses energy, diminishing the magnitude of the velocities. The velocity continues to decrease as the water moves up. This can result in very different degrees of mixing between the lower and higher regions. Tian and Roberts (2008) using LIF measurements observed a similar behavior for tanks with $H / D=2.5$. They found that the flow separates into two regions, with higher concentrations in the lower region, and lower concentrations in the upper region. Mixing between these two regions was slow, resulting in longer mixing times. Furthermore, there is a tendency for two recirculation zones ( $x z$-planes) to appear at lower regions of the tank (this recirculation zones are divided by the inlet jet). In the higher regions, these zones tend to merge and form a larger recirculation zone at the upper part of the tank (where the inlet jet influence is less significant). For the vertical inlet, it is possible to observe that the magnitudes of the velocities are more uniform throughout the tank. A big recirculation zone can be observed around an axis parallel to the $x$ axis. High velocities were found near the inlet, the outlet, and in the outer parts of the recirculation regions. Very low velocities were observed in the central areas of the re-circulation regions.

\section{Hydraulic indicators}

Table 4 presents the main effects of $M$ and inlet orientation and their interactions on $\theta_{10}, M_{2}, \mathrm{MI}$, and $\mathrm{X}$ for $H / D=4$. Figure 9 shows the pareto chart of the effects of the $2^{2}$ factorial design over $\theta_{10}, M_{2}$, MI, and $X$ for $H / D=4$. The values of $\theta_{10}$ were low (the average is equal to 0.0622), indicating the presence of intense short-circuiting. The short-circuiting average time was shorter for $H / D=4$ in comparison to $H / D=0.25$. The effect of the inlet orientation was statistically significant and $\theta_{10}$ increases by 0.110 as the inlet orientation changed from horizontal to vertical. Inlet momentum and its interaction with the inlet orientation did not present a statistically significant contribution.

With respect to $M_{2}$, the average is 0.621 . This is almost the same average value than that observed for $H / D=0.25$. The mixing index was in the range of $0.427-0.850$ (Table 2), i.e., a flow regime between transitional (between mixed and plug) and completely mixed. The pareto chart shows that the main effects of $M$ and IO and their
$D=4$. Again, $U / U_{\text {inlet }}$ was used to analyze the flow patterns of the tanks. For the horizontal inlet, the behavior at the lower regions of the tank was similar to the one found 
Table 4 Average and main effects of $M$ and IO and their higher order interactions of the 22 factorial design on the $\theta_{10}, M_{2}$, MI, and $X$ for $H /$ $D=4$

\begin{tabular}{|c|c|c|c|c|}
\hline Effect & $\theta_{10}$ & $M_{2}$ & MI & $X$ \\
\hline Average effect & 0.0622 & 0.621 & 0.250 & 0.444 \\
\hline \multicolumn{5}{|l|}{ Main effects } \\
\hline$M$ & +0.008 & -0.143 & -0.050 & +0.001 \\
\hline IO & +0.110 & -0.280 & -0.050 & -0.108 \\
\hline \multicolumn{5}{|c|}{ Two-factor interactions } \\
\hline$M-\mathrm{IO}$ & -0.009 & +0.034 & -0.007 & +0.017 \\
\hline
\end{tabular}

interaction do not significantly affect the mixing indicator $M_{2}$ (Fig. 9).

Regarding MI, the average value was 0.250 , not so different from the average value of 0.245 noted for $H /$ $D=0.25$. The MI values are in the range of $0.194-0.292$ (Table 2). All main effects and interactions were insignificant for MI (Fig. 9).

Again, considering $k=0.5 \mathrm{day}^{-1}$ (Grayman 2000). The fraction of disinfectant varied from 0.381 to 0.507 (Table 2). The average $X$ was 0.444 . Compared to the $H /$ $D=0.25$ tanks, the $H / D=4$ tanks reduced the average water quality by about $19 \%$. $X$ decreased when inlet orientation changed from horizontal to vertical by a maximum of $21.7 \%$. The main effect of inlet momentum and its interaction with inlet orientation were not statistically significant for $X$.

In summary, the strongest influence on the hydraulic efficiency was, once again, the inlet orientation. The effects of inlet momentum and the inlet momentum-inlet orientation interaction appeared small (statistically insignificant). Considering the effect of the inlet orientation, similar results have been reported in laboratory experiments (Tian and Roberts 2008). These studies, however, as mentioned before, evaluated hydraulic efficiency using the mixing time indicator and they did not affirm the relative importance of inlet orientation, inlet momentum and their interaction. Regarding the water quality efficiency, the strongest influence was also the inlet orientation. Since the strongest influence on hydraulic and water quality efficiencies is the same, at least one hydraulic index should demonstrates good correlation to effluent disinfectant fraction $X$. This is confirmed by the $R^{2}$ value of 0.787 for the mixing index and the $R^{2}$ value of 0.986 for the shortcircuiting index (Fig. 10). Again, the moment index does not demonstrate good correlation with $X$. Therefore, the use of short-circuiting and mixing indexes could be simple indicators of the water quality in storage tanks with $H / D=4$.
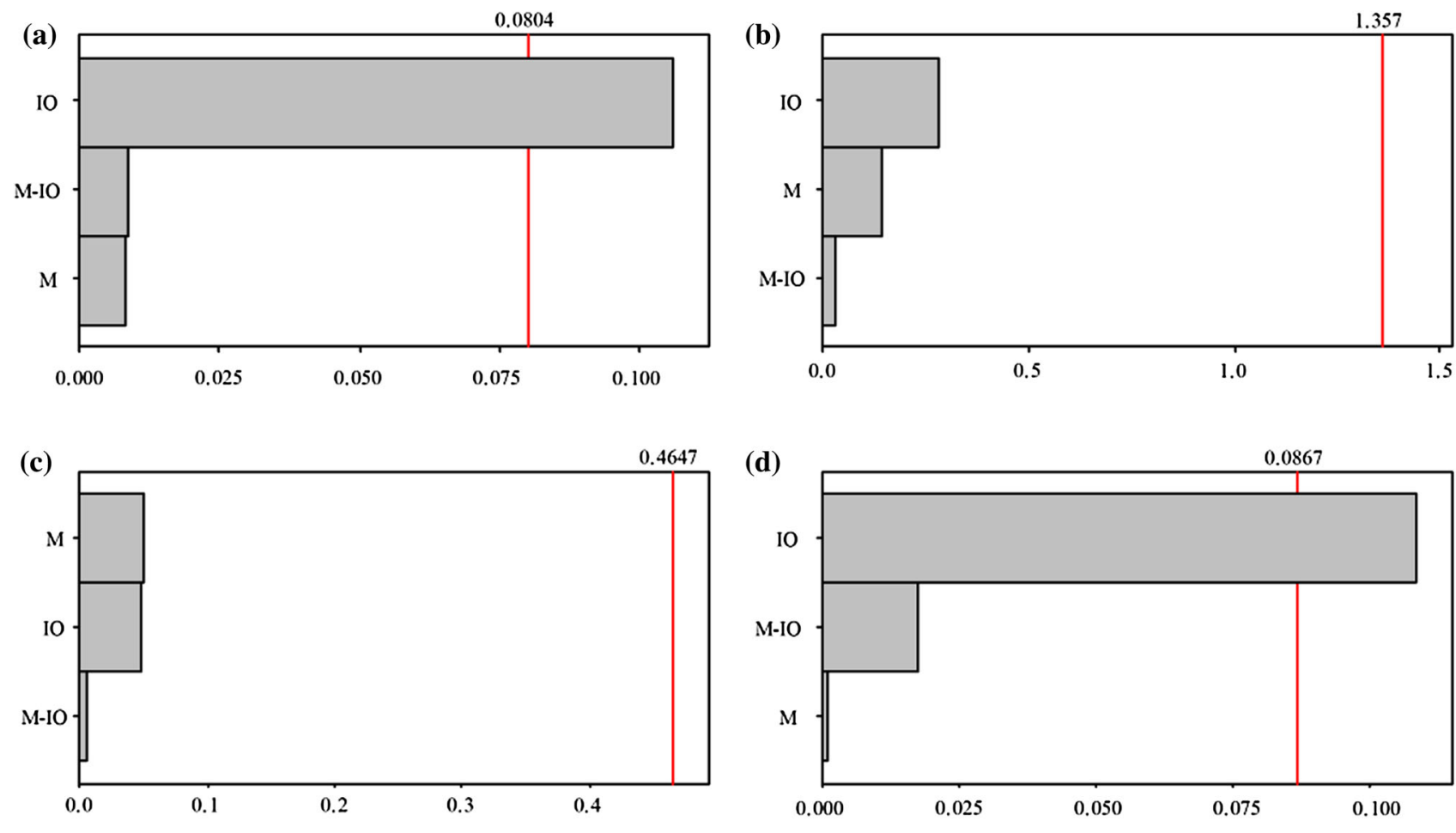

Effect

M - Inlet Momentum

IO - Inlet Orientation

Fig. 9 Pareto chart of the effects of the 22 factorial design over: a $\theta_{10} ; \mathbf{b} M_{2}$; $\mathbf{c}$ MI; and $\mathbf{d} X$; for $H / D=4$ 


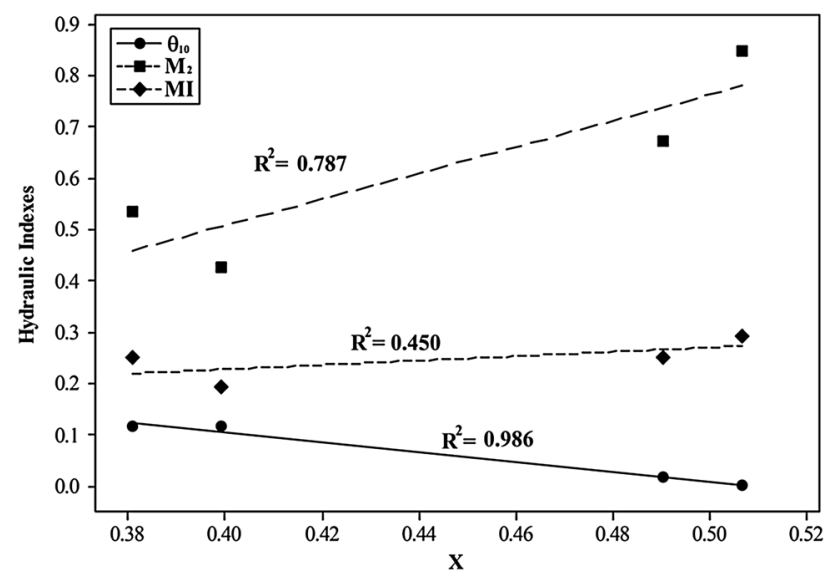

Fig. 10 Hydraulic indices plotted vs. effluent disinfectant fraction, $X$, for $H / D=4$. Regression lines are displayed with $R^{2}$ values for $\theta_{10}$, $M_{2}$, and $\mathrm{MI}$

\section{Conclusions}

CFD was applied to determine the empirical effects of inlet momentum and inlet orientation upon the hydraulic efficiency and the water quality of water storage tanks using a factorial design. For a small depth-to-diameter ratio $(H /$ $D=0.25$ ), the most important factor for hydraulic efficiency was the inlet orientation. Inlet momentum and the interaction between inlet momentum and inlet orientation also had an influence on the hydraulic efficiency. The effect of inlet orientation upon mixing is much stronger for a high inlet momentum than for a low inlet momentum. Regarding the water quality efficiency, the strongest influence was the inlet momentum. Inlet orientation and the interaction inlet orientation-inlet momentum are not significant. Since the order of importance of the factors that influence the hydraulic efficiency vary from those that influence the water quality efficiency, none of the hydraulics indexes demonstrated good correlation to water quality. For large depth-todiameter ratio $(H / D=4)$, the inlet orientation had the strongest influence on both the hydraulic efficiency and the water quality. None of the other factors were significant. The short-circuiting and mixing indexes presented a good correlation with the effluent disinfectant fraction and could be used to indicate the water quality for large depth-to-diameter ratio storage tanks.

Acknowledgments The authors acknowledge the support of FUNDECT/CNPq N ${ }^{\circ}$ 05/2011—PPP. Furthermore, Manoel Xavier would like to thank $\mathrm{CNPq}$ for personnel funding.

Open Access This article is distributed under the terms of the Creative Commons Attribution 4.0 International License (http:// creativecommons.org/licenses/by/4.0/), which permits unrestricted use, distribution, and reproduction in any medium, provided you give appropriate credit to the original author(s) and the source, provide a link to the Creative Commons license, and indicate if changes were made.

\section{References}

ABNT (Brazilian Association of Technical Standards) (1994) NBR 12217: project of water distribution reservoir for public supply of water-Procedure

ANSYS Inc. (2012) CFX-pre users guide release 14.5

AWWA (American Water Works Association) (2002) Finished water storage tanks. AWWA, Washington

Brown LC, Mac Berthouex P (2010) Statistics for environmental engineers. CRC Press, Boca Raton

Dakshinamoorthy D, Khopkar AR, Louvar JF, Ranade VV (2006) CFD simulation of short stopping runaway reactions in vessels agitated with impeller and jets. J Loss Prev Process Ind 19:570-581

Grayman WM (2000) Water quality modeling of distribution system storage facilities. AWWA, Washington

Kalaichelvi P, Swarnalatha Y, Raja T (2007) Mixing time estimation and analysis in a jet mixer. ARPN J Eng Appl Sci 2(5):35-43

Manjula P, Kalaichelvi P, Dheenathayalan K (2010) Development of mixing time correlation for a double jet mixer. J Chem Technol Biotechnol 85(1):115-120

Marek M, Stoesser T, Roberts PJ, Weitbrecht V, Jirka GH (2007) CFD modeling of turbulent jet mixing in a water storage tank. In: Proceedings of the Congress-International Association for Hydraulic Research, p. 551

Maruyama T, Ban Y, Mizushina T (1982) Jet mixing of fluids in tanks. J Chem Eng Jpn 15(5):342-348

MINITAB (2015). MINITAB ${ }^{\circledR} 17$ Support. http://support.minitab.com/ en-us/minitab/17/topic-library/modeling-statistics/doe/factorialdesign-plots/what-is-a-pareto-chart-of-effects/. Accessed 16 June 2015

Montgomery DC, Runger GC (2003) Applied statistics and probability for engineers. Wiley, Danvers

Palau G, Weitbrecht V, Stoesser T, Bleninger T, Hofmann B, Maier M, Roth K (2007) Numerical Simulations to predict the hydrodynamics and the related mixing processes in water storage tanks. In: proceedings IAHR congress, Venice

Patwardhan AW (2002) CFD modeling of jet mixed tanks. Chem Eng Sci 57(8):1307-1318

Raja T, Kalaichelvi P, Ananthraman N (2007) Development of CFD model for optimum mixing in jet mixed tanks. J Sci Ind Res 66(7):522-527

Raja T, Kalaichelvi P, Ananthraman N (2008) An experimental and CFD investigation of the effect of nozzle inclination and twisting in a double jet mixed tank. Int J Appl Eng Res 3(10):1337-1352

Roberts PJW, Tian X, Lee S, Sotiropoulos F, Duer M (2006) Mixing in storage tanks - draft final report, AWWA Research Foundation

Rossman LA, Grayman WM (1999) Scale-model studies of mixing in drinking water storage tanks. J Environ Eng 125(8):755-761

Shivaram P (2007) Mixing in water supply service tanks and reservoirs. Dissertation, The University of Western Australia

Stamou A (2002) Verification and application of a mathematical model for the assessment of the effect of guiding walls on the hydraulic efficiency of chlorination tanks. J Hydroinform $4: 245-254$

Stamou AI (2008) Improving the hydraulic efficiency of water process tanks using CFD models. Chem Eng Process 47(8):1179-1189

Teixeira EC, do Nascimento Siqueira R (2008) Performance assessment of hydraulic efficiency indexes. $J$ Environ Eng 134(10):851-859

Tian X, Roberts PJ (2008) Mixing in water storage tanks. I: no buoyancy effects. J Environ Eng 134(12):974-985

United States Environmental Protection Agency (2002) Finished Water Storage Facilities. AWWA, Washington 
Van der Walt JJ (2002) The modelling of water treatment process tanks. Doctoral dissertation, Rand Afrikaans University

Wahl MD, Brown LC, Soboyejo AO, Martin J, Dong B (2010) Quantifying the hydraulic performance of treatment wetlands using the moment index. Ecol Eng 36(12):1691-1699

Walski TM (2000) Hydraulic design of water distribution storage tanks. In: Mays LW (ed) Water distribution systems handbook. McGraw-Hill Professional, New York, pp 10.1-10.20

Werner TM, Kadlec RH (1996) Application of residence time distributions to stormwater treatment systems. Ecol Eng 7(3):213-234

Xavier MLM, Lima PHS, Janzen JG (2014) Impact of inlet and outlet configurations on the mixing behavior in water storage tanks. Engenharia Sanitária Ambiental 19(3):315-324
Zhang JM, Khoo BC, Lee HP, Teo CP, Haja N, Peng KQ (2012) Effects of baffle configurations on the performance of a potable water service reservoir. J Environ Eng 138(5):578-587

Zhang JM, Khoo BC, Lee HP, Teo CP, Haja N, Peng KQ (2013) Numerical simulation and assessment of the effects of operation and baffling on a potable water service reservoir. J Environ Eng 139(3):341-348

Zhang JM, Lee HP, Khoo BC, Pen KQ, Zhong L, Kang CW, Ba T (2014) Shape effect on mixing and age distributions in service reservoirs. J AWWA 106(11):E481-E491

Zughbi HD, Rakib MA (2004) Mixing in a fluid jet agitated tank: effects of jet angle and elevation and number of jets. Chem Eng Sci 59(4):829-842 